\title{
Development of a Method for Measuring Phytanic Acid as a Lifestyle-related Disease Biomarker in Rat Serum Using Ultra-fast Liquid Chromatography-Ultraviolet Spectrophotometry Combined with a Modified 2-Nitrophenylhydrazine Derivatization Method
}

\author{
Aoi Miyamoto,* Takahiko Aoyama,* Masahiro OKamura,** Noboru FukudA,** Takahiro Ueno,** \\ Masanori ABE, ** and Yoshiaki Matsumoto*广 \\ *School of Pharmacy, Nihon University, 7-7-1 Narashinodai, Funabashi, Chiba 274-8555, Japan \\ **Division of Nephrology, Hypertension and Endocrinology, Nihon University School of Medicine, 30-1 Oyaguchi \\ Kami-chou, Itabashi, Tokyo 173-8610, Japan
}

\begin{abstract}
A simple and rapid ultra-fast liquid chromatography-ultraviolet spectrophotometry (UFLC-UV) method combined with modified 2-nitrophenylhydrazine (2-NPH) derivatization was developed for determining phytanic acid (Phy) in rat serum. Serum Phy and heptadecanoic acid (the internal standard) were derivatized by 2-NPH at ambient temperature for 20 min and extracted in $n$-hexane. After extracting derivatized Phy (D-Phy) and derivatized IS from the reaction mixture, the extracts were separated with a YMC-Pack C8 column $(150 \times 3.0 \mathrm{~mm}$ i.d., S-3 $\mu \mathrm{m})$ using an isocratic mobile phase comprised of acetonitrile: $\mathrm{H}_{2} \mathrm{O}(90: 10 ; \mathrm{pH} 4.4)$ at $0.5 \mathrm{~mL} / \mathrm{min}$. The detection wavelength was $228 \mathrm{~nm}$. Linearity was observed over $1-20 \mu \mathrm{g} / \mathrm{mL}(r=0.9997)$. The intra- and inter-day reproducibilities of D-Phy measurements were $\leq 13.0 \%$. To our knowledge, this is the first report of the quantitative and qualitative measurement of serum Phy using 2-NPH derivatization and UFLC-UV. This method can be performed rapidly under mild conditions.
\end{abstract}

Keywords Phytanic acid, UFLC-UV, 2-nitrophenylhydrazine

(Received September 20, 2016; Accepted November 1, 2016; Published March 10, 2017)

\section{Introduction}

High prevalence rates are associated with several lifestylerelated diseases, such as hypertension, hyperlipidemia, and diabetes. These diseases are major causes of arteriosclerosis, which is the leading cause of death among Japanese. The pathological conditions of these diseases vary widely, and clarification of the condition is desired. Because of the necessity for research on the treatment and prevention of lifestyle-related diseases, approaches using animal models have been developed. ${ }^{1}$ The expression level of the acyl-CoA oxidase 2 (ACOX2) gene, which is involved in $\beta$-oxidation in the kidneys of spontaneously hypertensive rats (SHR/Izm), was significantly higher than that in control model rats (WKY/Izm). ${ }^{2}$ The substrate for ACOX2 is pristanic acid, which is derived from Phy. Phy is a branched, long-chain fatty acid with 20 carbon atoms and is derived mainly from green and yellow vegetables and meats. Phy can be used as a biomarker to diagnose Refsum disease. ${ }^{3}$ Blood pressure in SHR/Izm rats was significantly higher than that in WKY/Izm rats. ${ }^{4}$ These results indicated that measuring Phy concentrations in serum from SHR/Izm and WKY/Izm rats might help elucidate the relationship between high blood pressure and Phy levels. The measurement might also make the prediction of ACOX2 increases possible. Establishment of a

† To whom correspondence should be addressed.

E-mail: matsumoto.yoshiaki@ nihon-u.ac.jp simple and rapid method to monitor Phy concentrations in serum should help provide a useful means for clarifying the mechanisms of lifestyle-related diseases. Research on developing a Phy assay system was initiated based on this consideration.

Determination of Phy in biological samples has been reported. The detection methods used were gas chromatography (GC),, 6 GC-mass spectrometry (GC-MS), ${ }^{7,8}$ high-performance liquid chromatography-atmospheric pressure chemical ionizationtandem mass spectrometry (LC-APCI-MS/MS), ${ }^{9}$ and ultraperformance liquid chromatography (UPLC)-MS/MS. ${ }^{10}$ GC is used for measuring components in samples that tend to become vaporized. GC-MS and LC-MS/MS require derivatization procedures (such as methylation or hydrolysis), which involve incubation conditions lasting $1-2 \mathrm{~h}$ at $60-100^{\circ} \mathrm{C}$. Sample preparation for these methods is time-consuming. In this study, an ultra-fast liquid chromatography-ultraviolet spectrophotometry (UFLC-UV) method was used in combination with a modified 2-nitrophenylhydrazine (2-NPH)-derivatization method in order to develop a simple and rapid method for Phy analysis.

\section{Experimental}

Reagents and solutions

Phy was purchased from Sigma-Aldrich Japan (Japan). Acetonitrile, methanol, ethanol, $n$-hexane, and distilled water were all of HPLC grade and were obtained from Kanto Chemical 


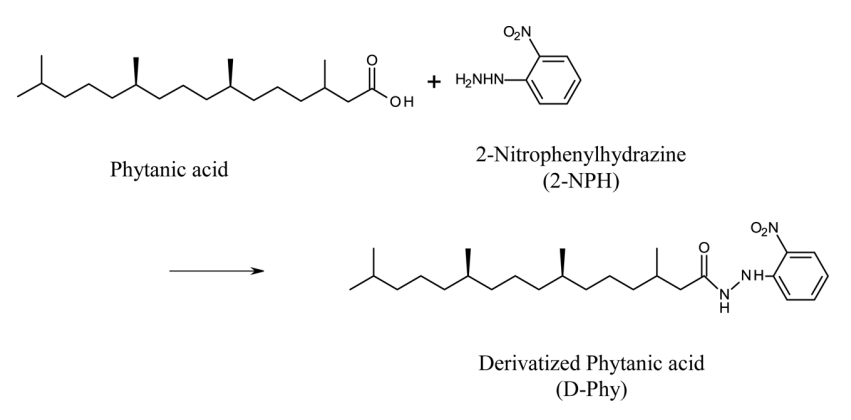

Fig. 1 Derivatization reaction of phytanic acid.

Co, Inc. (Japan). Heptadecanoic acid was obtained from Tokyo Chemical Industry Co., Ltd. (Japan) and used as the internal standard (IS). The YMC Fatty Acid Analysis Kit and a YMC Duo-filter (4-mm inner diameter) were purchased from YMC Co., Ltd. (Japan). Wister rat serum was purchased from Charles River Laboratories Japan, Inc. (Japan).

\section{Chromatography conditions and instruments}

The UFLC system consisted of a Prominence UFLC (20A Series) (Shimadzu, Japan). Derivatized Phy (D-Phy) and derivatized IS (D-IS) were analyzed on a YMC-Pack C8 column $(150 \times 3.0 \mathrm{~mm}$ i.d., $\mathrm{S}-3 \mu \mathrm{m}){ }^{11}$ The column was maintained at $35^{\circ} \mathrm{C}$. The isocratic mobile phase comprised acetonitrile: $\mathrm{H}_{2} \mathrm{O}$ (90:10; $\mathrm{pH} 4.4$, adjusted by $\mathrm{HCl})^{11}$ at a flow rate of $0.5 \mathrm{~mL} / \mathrm{min}$. The injection volume was $10 \mu \mathrm{L}$, and the detection wavelength was set to $228 \mathrm{~nm}$.

\section{Preparation of standards and working samples}

A primary stock standard solution of Phy $(1 \mathrm{mg} / \mathrm{mL})$ was prepared in ethanol, and diluted in ethanol to obtain a series of working solutions $(10,50,100$, and $200 \mu \mathrm{g} / \mathrm{mL})$. An IS primary stock standard solution $(1 \mathrm{mg} / \mathrm{mL})$ was dissolved in ethanol, and diluted to $2 \mu \mathrm{g} / \mathrm{mL}$ in ethanol for derivatization reactions. Each primary stock solution was stored at $4^{\circ} \mathrm{C}$.

Serum calibration standards were freshly prepared by spiking $45 \mu \mathrm{L}$ of blank pooled rat serum pre-thawed at room temperature with $5 \mu \mathrm{L}$ of working Phy solutions (final concentrations: 1,5 , 10 , and $20 \mu \mathrm{g} / \mathrm{mL}$ ). The blank rat serum was stored at $-20^{\circ} \mathrm{C}$ until use.

\section{Derivatization reaction}

The YMC Fatty Acid Analysis Kit is composed of four reagents; Reagent A (derivatization reagent, 2-NPH solution), Reagent B (condensing agent, 1-ethyl-3-[3-dimethylaminopropyl] carbodiimide solution), Reagent C (reaction stop solution, alkaline solution), and Reagent $\mathrm{D}$ (neutralization reagent, acidic buffer). Although the derivatization reaction was performed based on the YMC Fatty Acid Analysis Kit manual, the protocol indicated no precedent application for Phy. Modifications of the derivatization procedure were made for increased derivatization. The modified derivatization procedure was as follows. To $50 \mu \mathrm{L}$ of serum calibration sample or blank serum, $200 \mu \mathrm{L}$ of IS solution $(2 \mu \mathrm{g} / \mathrm{mL}), 200 \mu \mathrm{L}$ of Reagent A, and $200 \mu \mathrm{L}$ of Reagent $\mathrm{B}$ were added in a stoppered test tube and mixed for $20 \mathrm{~min}$ at room temperature in a shaker (double shaker NR-3, Taitec Corporation) to prevent the mixture from solidifying. Subsequently, Reagent $C$ was added and the solution was mixed vigorously with a vortexer. Next, Reagent $\mathrm{D}$ was immediately added to the mixture, after which $5 \mathrm{~mL}$ of $n$-hexane was added to the mixture to extract D-Phy (Fig. 1) and D-IS. This mixture
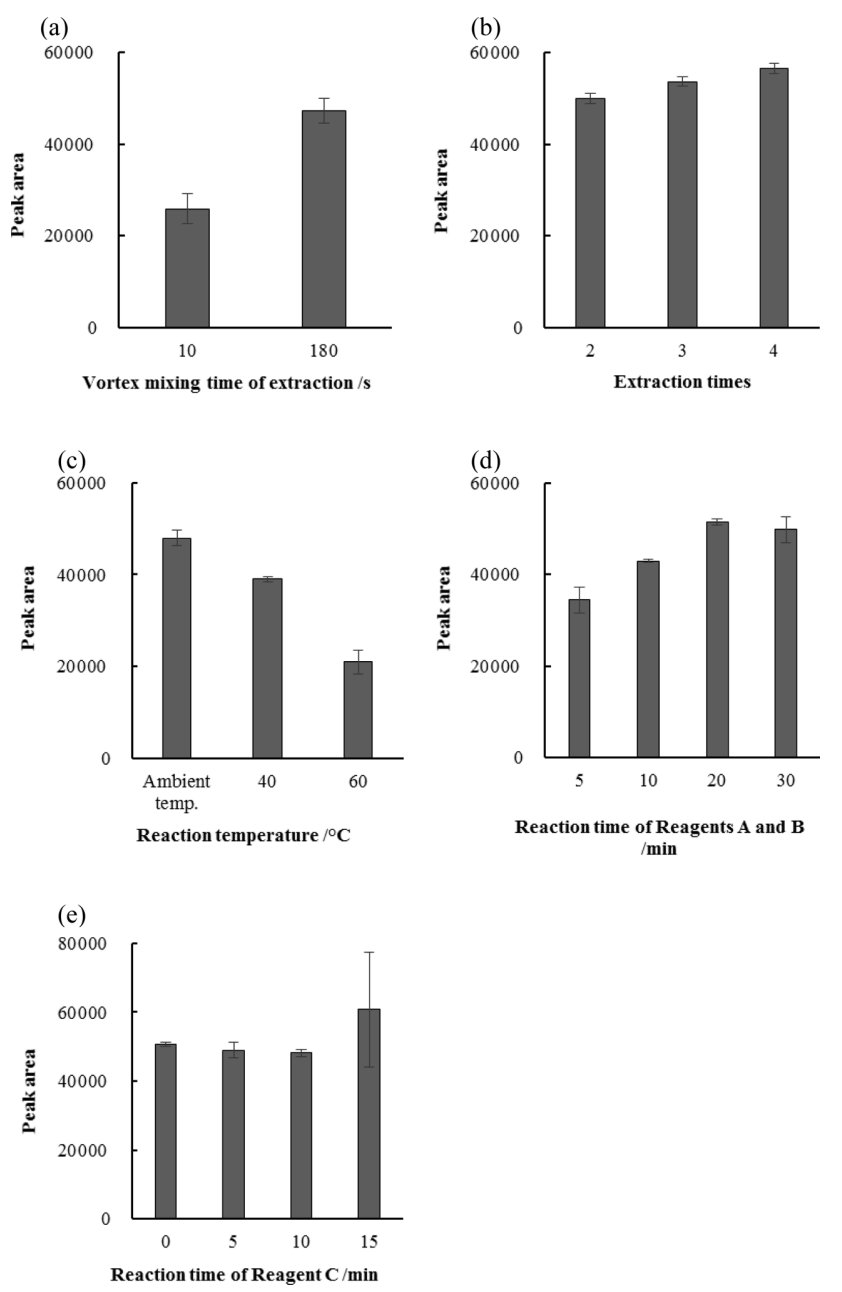

Fig. 2 Effect of the derivatization conditions on the peak area of derivatized phytanic acid. These parameters included (a) the vortex mixing time used for extraction, (b) the extraction time, (c) the reaction temperature with Reagents $\mathrm{A}$ and $\mathrm{B}$, (d) the reaction time with Reagents A and B, and (e) the reaction time with Reagent C.

was vortexed for $180 \mathrm{~s}$ and centrifuged at $3000 \mathrm{rpm}$ for $5 \mathrm{~min}$. Three milliliters of the supernatant were transferred to another test tube and evaporated to dryness. This extraction step was repeated three times. The residue was reconstituted in $200 \mu \mathrm{L}$ of methanol and filtrated using a Duo-filter. Ten microliters of the filtrated solution were injected into the UFLC system for analysis. The same procedure was used for all samples.

It was believed that little endogenous Phy and IS exist in normal healthy experimental animals. However, since Phy and IS were detected in blank serum, the measured values were calculated by subtracting the peak area of blank samples from working samples in all optimizations and validations.

\section{Results and Discussion}

\section{Optimization of the derivatization conditions}

Optimal experimental conditions having good reproducibility were determined as the protocol resulting in the largest D-Phy peak area value with the smallest standard deviation (SD), using the UFLC system. The Phy concentration in a rat serum sample used for this study was $10 \mu \mathrm{g} / \mathrm{mL}$. We mainly investigated the reaction time and temperature used when treating serum with 
(a)

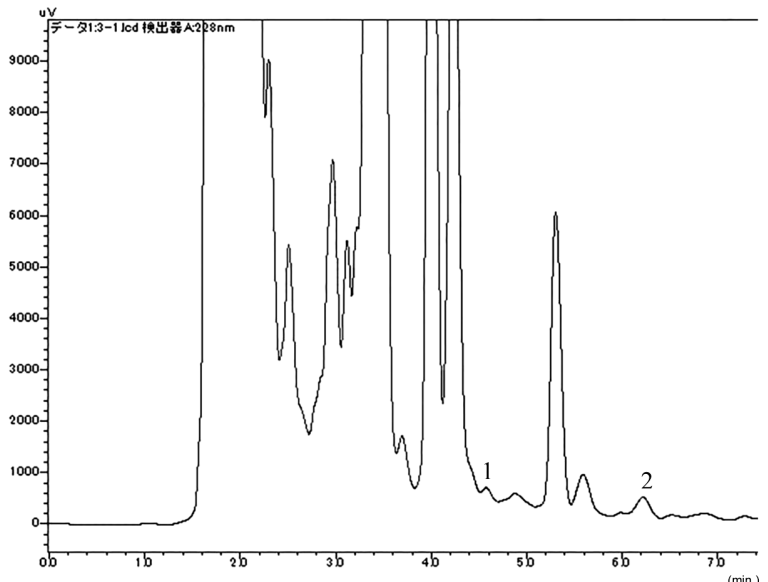

(b)

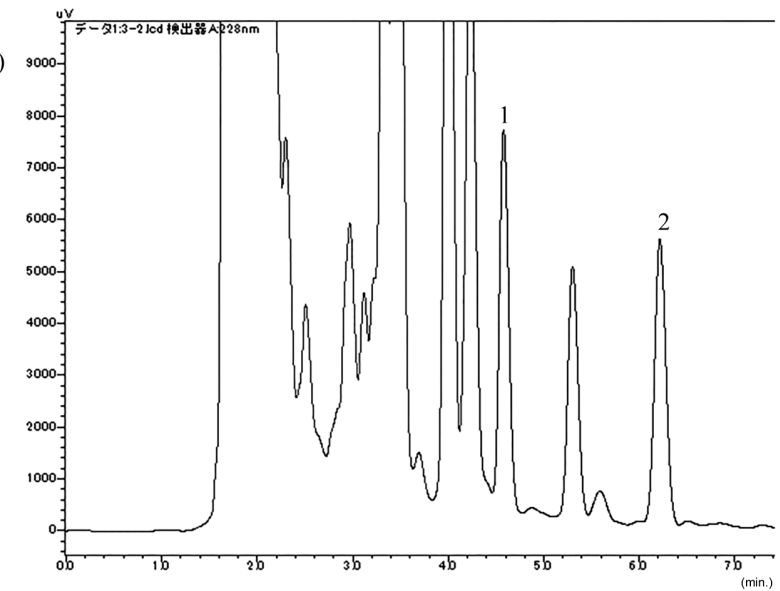

Fig. 3 Chromatograms of serum after derivatization of (a) blank serum and (b) phytanic acid and IS added to the serum. 1: Derivatized IS (IS concentration: $2.0 \mu \mathrm{g} / \mathrm{mL}$ ), retention time: $4.5 \mathrm{~min} .2$ : Derivatized phytanic acid (phytanic acid concentration: $100 \mu \mathrm{g} / \mathrm{mL}$ ) retention time: $6.2 \mathrm{~min}$.

derivatization reagents, and the mixing time and number of D-Phy-extraction steps used following derivatization. The results of these experiments are shown in Fig. 2. The optimized conditions are described in detail in the Experimental section. Serum was incubated for $20 \mathrm{~min}$ at ambient temperature with the Reagents A and B mixture (Fig. 2(d)). No extended reaction time was necessary with Reagent C (Fig. 2(e)). D-Phy was extracted three times (Fig. 2(b)). Chromatograms of the derivatives are shown in Fig. 3. The peak regarded as D-Phy was fractionated and identified by electrospray ionization-mass spectrometry (Xevo G2S-QTof, Waters) by the Chemical Analysis Center, School of Pharmacy, Nihon University (Fig. 4).

\section{Linearity of the calibration curves and reproducibility}

D-Phy measurements were made in the range of $1-20 \mu \mathrm{g} / \mathrm{mL}$ in rat serum to generate a calibration curve. The curves were proportional to the concentration of the analyte over the range of $1-20 \mu \mathrm{g} / \mathrm{mL}$. A linear relationship $(r=0.9997)$ was observed between the D-Phy peak area divided by the D-IS peak area and each Phy concentration.

The reproducibility of D-Phy measurements was expressed as the coefficient of variation $(\mathrm{CV})$ and is listed in Table 1. Intraand inter-day $\mathrm{CV}$ values were $\leq 13.0 \%$. Recovery following the derivatization reaction was not examined because a D-Phy standard was not commercially available.

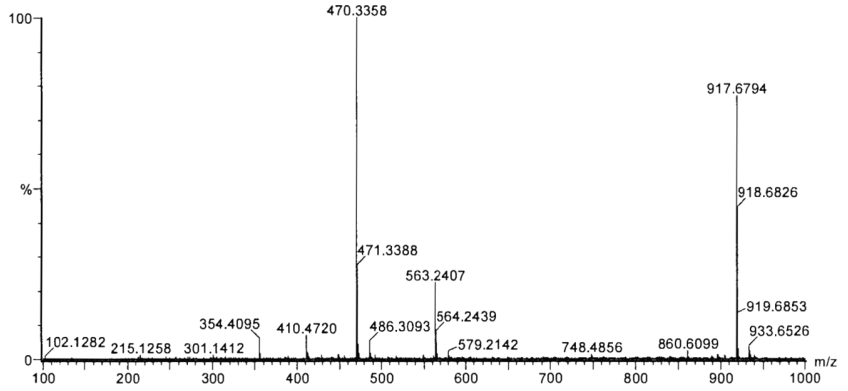

Fig. 4 Mass spectra of the peak regarded as derivatized phytanic acid. The $[\mathrm{M}+\mathrm{Na}]^{+}$and $[2 \mathrm{M}+\mathrm{Na}]^{+}$forms of derivatized phytanic acid $(\mathrm{m} / \mathrm{z}, 470.3$ and 917.7 , respectively) are indicated.

Table 1 Intra- and inter-day reproducibility of derivatized phytanic acid measurements

\begin{tabular}{|c|c|c|c|c|}
\hline \multirow{2}{*}{$\begin{array}{c}\text { Phytanic acid } \\
\text { concentration/ } \\
\mu \mathrm{g} \mathrm{mL}^{-1}\end{array}$} & \multicolumn{2}{|c|}{ Intra-day $(n=5)$} & \multicolumn{2}{|c|}{ Inter-day $(n=3)$} \\
\hline & $\begin{array}{c}\text { Mean peak } \\
\text { area ratio } \\
(\text { mean } \pm \mathrm{SD})\end{array}$ & $\begin{array}{c}\mathrm{CV}, \\
\%\end{array}$ & $\begin{array}{c}\text { Mean peak } \\
\text { area ratio } \\
(\text { mean } \pm \mathrm{SD})\end{array}$ & $\begin{array}{c}\mathrm{CV} \\
\%\end{array}$ \\
\hline 1 & $0.0228 \pm 0.0008$ & 3.43 & $0.0270 \pm 0.0010$ & 3.79 \\
\hline 5 & $0.0796 \pm 0.0038$ & 4.76 & $0.0905 \pm 0.0063$ & 6.70 \\
\hline 10 & $0.1564 \pm 0.0199$ & 12.7 & $0.1646 \pm 0.0215$ & 13.0 \\
\hline 20 & $0.2926 \pm 0.0282$ & 9.64 & $0.3053 \pm 0.0377$ & 12.3 \\
\hline
\end{tabular}

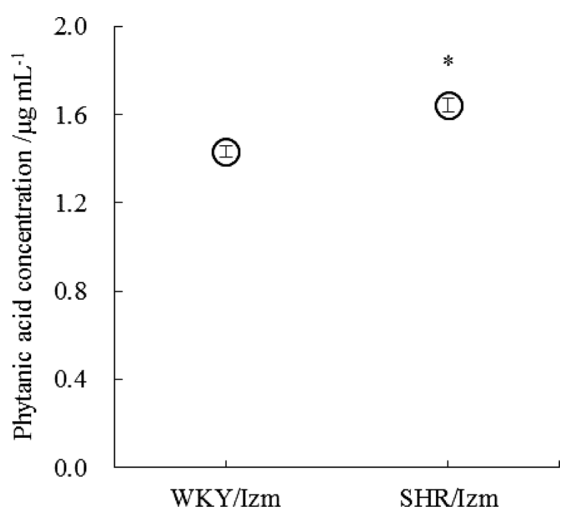

Fig. 5 Comparison of phytanic acid concentrations in WKY/Izm and SHR/Izm sera $(n=5)$. Each value represents the mean $\pm \mathrm{SD}$. $* p<0.01$, as determined by Student's t-test (compared with WKY/Izm rats).

\section{Application}

Sera from Wistar Kyoto rats (control rats: WKY/Izm) and spontaneously hypertensive rats (SHR/Izm) were analyzed by the UFLC-UV method developed in this study. Each rat $(n=5)$ was male and 5 weeks old. The blood samples were collected from the inferior vena cava. All rats were anaesthetized with isoflurane prior to sampling. They were acquired from the School of Medicine of Nihon University. The animal experiment was approved by the Animal Ethics Committee of the School of Medicine of Nihon University (Approval Number: AP11M019-2).

The results of the application study are shown in Fig. 5 . Comparisons of Phy concentrations in WKY/Izm and SHR/Izm sera were made using the F-test and Student's t-test. Statistically 
significant differences were observed between SHR/Izm rats $(1.64 \pm 0.030 \mu \mathrm{g} / \mathrm{mL})$ compared to WKY/Izm rats $(1.43 \pm$ $0.027 \mu \mathrm{g} / \mathrm{mL})(p<0.01)$. Though concentration of Phy in rats (unknown phyletic line) determined by GC was $1.9 \mu \mathrm{g} / \mathrm{mL}$, ${ }^{6}$ the concentration in SHR/Izm and WKY/Izm rats had not been reported. The SHR/Izm rats used for this investigation were 5 weeks old. The blood pressure of the SHR/Izm rats increased with age, while those of WKY/Izm rats did not change. ${ }^{4}$ The Phy level, as determined using the developed system, was significantly higher in SHR/Izm rat serum than in WKY/Izm serum. This result suggested that monitoring the Phy level in the serum may provide a useful means for clarifying the mechanism underlying the onset of hypertension.

\section{Conclusion}

A method for detecting Phy in rat serum using 2-NPH as a derivatization reagent and a UFLC-UV system was developed. Analysis of the Phy concentration in WKY/Izm and SHR/Izm sera was conducted using the method. To our knowledge, this is the first report of the quantitative measurement of Phy using a combination of 2-NPH derivatization and UFLC-UV. Although many Phy detection methods have been reported, ${ }^{5-10}$ mild conditions for the derivatization step have not been reported. In this study, we developed a detection method employing mild derivatization conditions, which could be performed relatively quickly with a general-purpose UFLC-UV system. Therefore, this Phy measurement method should be widely applicable for studies related to Phy.

\section{Acknowledgements}

The authors thank Dr. Koichi Metori (Analytical Center, School of Pharmacy, Nihon University) for performing the mass measurements. The authors also thank Yuki Ota, B.Sc., Akari
Usami, B.Sc., and Yui Kawade, B.Sc. for providing technical assistance.

\section{Conflict of Interest}

The authors have no conflict of interest directly relevant to the content of this article.

\section{References}

1. A. Grundt, C. Grundt, S. Gorbey, M. A. Thomas, and B. Lemmer, Physiol. Behav., 2009, 97, 341.

2. M. Okamura, T. Ueno, A. Tsunemi, S. Tanaka, T. Maruyama, M. Abe, K. Okada, M. Endo, K. Matsumoto, N. Fukuda, and M. Soma, Jpn. J. Nephrol., 2015, 57, 596.

3. "Refsum Disease Synonyms: Adult Refsum Disease, Refsum Syndrome", http://www.ncbi.nlm.nih.gov/books/ NBK1353/.

4. S. Fukuda, S. Tsuchikura, and H. Iida, Exp. Anim., 2004, $53,67$.

5. P. J. Jackson and J. A. Samondsen, J. Chromatogr., 1985, $325,336$.

6. J. Avigan, Biochim. Biophys. Acta, 1966, 116, 391.

7. N. E. Allen, P. B. Grace, A. Ginn, R. C. Travis, A. W. Roddam, P. N. Appleby, and T. Key, Br. J. Nutr., 2008, 99, 653.

8. Y. Takemoto, Y. Suzuki, R. Horibe, N. Shimozawa, R. J. A. Wanders, and N. Kondo, Brain Dev., 2003, 27, 481.

9. M. Semeraro, C. Rizzo, S. Boenzi, M. Cappa, E. Bertini, G. Antonetti, and C. Dionisi-Vici, Clin. Chim. Acta, 2016, $458,159$.

10. O. Y. Al-Dirbashi, T. Santa, M. S. Rashed, Z. Al-Hassnan, N. Shimozawa, A. Chedrawi, M. Jacob, and M. AlMokhadab, J. Lipid Res., 2008, 49, 1855.

11. H. Miwa, C. Hiyama, and M. Yamamoto, J. Chromatogr., $\mathbf{1 9 8 5}, 321,165$. 